\title{
Tendências Recentes na União Europeia Relativamente às Emissões de Dioxinas para a Atmosfera
}

\author{
J O $\tilde{A}$ O C.M. B O R D A D O ${ }^{1}$

\section{A PROBLEMÁticA RECENTE RELATIVA ÀS EMISSÕES DE DIOXINAS}

Muito recentemente, novas pressões por parte do público devido a acidentes ou à divulgação de dados sobre saúde e toxicologia fizeram despoletar novos regulamentos e também novos processos industriais para o tratamento de gases contendo dioxinas e dibenzofuranos, os compostos policlorados de maior toxicidade actualmente conhecida [1], e que, por isso, constam da lista de substâncias químicas que se recomenda sejam banidas mesmo que tal implique uma modificação substancial nos processos industriais.

Em diversos países como a Bélgica e a França, onde ocorreram contaminações alimentares recentes, a pressão da opinião pública levou já à tomada de medidas para a redução das emissões gasosas destes compostos, fundamentalmente nas emissões das unidades de incineração.

Alguns países da União Europeia haviam já começado a desenvolver esforços nesse sentido e países como a Alemanha, Áustria, Holanda e Suécia começaram já a monitorizar regularmente essas emissões desde os finais da década de 80 , tendo sido possível constatar nítidas reduções, nomeadamente em resultado da instalação de unidades de tratamento de gases [2].

Naturalmente que na Bélgica e em França a pressão da opinião pública tem vindo a ser incrementada pela cobertura da imprensa e, fundamentalmente, da televisão dada ao assunto, o que tem vindo a fazer com que as autoridades oficiais tenham vindo a decretar medidas cada vez mais restritivas sobre algumas actividades industriais.

Por exemplo, na Flandres, foram fechadas em Dezembro de 1997, 5 unidades de incineração de resíduos sólidos urbanos, por ter sido excedido o limite da emissão de $0,1 \mathrm{ng}$ em equivalente tóxico por metro cúbico normal $\left(\mathrm{TEQ} / \mathrm{Nm}^{3}\right)$. Diversas unidades de incineração do mesmo tipo no

\author{
J O Ã O F.P. G O ME S 2
}

Norte da França foram também encerradas em 1998 por terem sido encontrados teores anormalmente elevados de dioxinas e dibenzofuranos no leite proveniente de quintas localizadas nas proximidades [3].

\section{VALORES-LIMITE DE EMISSÃO DE DIOXINAS}

Na verdade, a maior fonte de dioxinas e dibenzofuranos na União Europeia continuam a ser os incineradores de resíduos sólidos urbanos, alguns construídos há mais de 10 anos com tecnologias ultrapassadas, cuja contribuição para o total das emissões é estimada em cerca de $40 \%$ [3]. Em ordem decrescente de importância seguem-se as unidades de sinterização das siderurgias, unidades de combustão alimentadas a madeira ou resíduos lenhosos, incêndios florestais, emissões secundárias de produtos tratados com pentaclorofenol (PCP) e unidades de reciclagem de sucata automóvel e de metais não-ferrosos.

A instalação de equipamentos de depuração e controlo cada vez mais sofisticados deverá permitir que os níveis de emissão das instalações atrás referidas venham a decrescer significativamente no futuro próximo. Por esta ordem de ideias, será de esperar que esse tipo de procedimentos seja adoptado igualmente em relação aos incineradores de resíduos sólidos urbanos que poderão, assim. vir a tornar-se em fontes com contribuições mais reduzidas para as emissões globais de dioxinas e dibenzofuranos, como já acontece na Alemanha e na Holanda.

Nestes últimos países a atenção passou, então, a centrar-se na redução das emissões de outras fontes pontuais.

Contudo é importante realçar que nunca foi efectuada uma avaliação detalhada dos níveis de emissão das diversas fontes dos países da União Europeia. A maior parte das decisões sobre política ambiental e regulamentação dos níveis de emissão baseia-se em determinações efec- tuadas nos Estados Unidos, a partir dos quais são efectuadas extrapolações para os países da União Europeia o que, naturalmente, conduz a resultados falíveis e de base científica pouco aceitável.

Assiste-se assim, à abertura de um vasto leque de oportunidades às empresas e laboratórios capazes de efectuar estas determinações experimentais, reconhecida a necessidade de efectuar os inventários das emissões relativamente a estes compostos nos países da União Europeia, esperando-se ainda que este movimento alastre aos países do antigo bloco de leste, tendo em vista a sua integração na União Europeia [4]. Numa segunda fase, quando os inventários estiverem completos, ou pelo menos mais avançados, irá certamente assistir-se à necessidade do desenvolvimento e aplicação de tecnologias necessárias à redução das emissões de dioxinas por forma a verificar-se a conformidade com os valores-limite fixados pela legislação.

Como se sabe, a nível da Comissão Europeia é a Direcção-Geral XI que procede à fixação dos valores-limite de emissão para fontes estacionárias. Precisamente pela inexistência de dados sobre as emissões de dioxinas na União Europeia, esta Direcção Geral iniciou um estudo de inventariação das emissões de dioxinas e identificação das principais fontes emissoras. Os regulamentos mais antigos a este nível são a Directiva 94/67/CE segundo a qual todos os incineradores de resíduos perigosos (tanto novos, como existentes) deverão cumprir com um limite de emissão de $0,1 \mathrm{ng}$ $\mathrm{TEQ} / \mathrm{Nm}^{3}$ nos gases e um limite de emissão de $0,5 \mathrm{ng} / \mathrm{l}$ nas emissões em fase líquida.

Em Outubro de 1998 foram introduzidos novos regulamentos para as instalações que procedem à queima de resíduos não perigosos, o que inclui a incineração e co-incineração de uma grande quantidade de resíduos tais como pneus, lamas de depuração, certos tipos de resíduos hospitalares, óleos usados e solven- 
tes orgânicos. Este regulamento entrou em vigor em 1999 para instalações novas e em 2007 para instalações já existentes. Em ambos os casos o valor-limite de emissão para dioxinas é fixado em $0,1 \mathrm{ng}$ $\mathrm{TEQ} / \mathrm{Nm}^{3}$.

Alguns tipos de instalações industriais, actualmente já reconhecidas como fontes de emissões de dioxinas, não têm ainda valores-limite de emissão fixados, embora esses valores se encontrem actualmente em discussão. Estão nesse caso fontes das indústrias de fusão secundária de alumínio, sinterização de metais ferrosos e fornos de cimento que utilizem combustíveis alternativos. Por exemplo, na Alemanha foi já adoptado um valor-limite de emissão de $0,1 \mathrm{TEQ} / \mathrm{Nm}^{3}$ que entrou em vigor para crematórios em 1 de Maio de 2000.

Estima-se que a implementação das medidas necessárias ao cumprimento dos valores-limite irá custar mais do que 550 milhões de Euro por ano, estimando-se também que os benefícios ambientais e de saúde conduzirão a um lucro directo de 260 milhões Euro por ano [4].

Naturalmente que os governos nacionais ou mesmo locais podem impor valores-limite de emissão mais restritivos o que implica que, para ser avaliada a conformidade deverá ser tomado em consideração o avanço do estado-da-arte relativamente à quantificação dessas emissões, em particular no que diz respeito aos limites inferiores de detecção.

\section{EVOLUÇÃO TECNOLÓGICA RELATIVAMMNTE À REDUÇÃO DAS EMISSÕES DE DIOXINAS}

Historicamente, assistiu-se inicialmente à redução das emissões de dioxinas através da utilização de torres contendo carvão activado em leito fixo, soluções estas de "fim-delinha", eficazes na redução dos níveis de emissão, mas com elevados custos de investimento e de operação.
Reconhecida a importancia de utilizar carvão activado na adsorção de dioxinas e dibenzofuranos, os sistemas evoluiram para doseamento contínuo de uma lama de carvão ou de mistura de carvão e cal, normalmente após um precipitador electrostático.

À medida que os operadores e projectistas das instalações foram procurando sistemas igualmente eficazes, mas de menor custo, desenvolveram-se conceitos mais simples tais como instalações equipadas com sistemas de "absorção seca" que consideram um reactor de concepção optimizada e filtros de mangas, cumprindo igualmente com os valores-limite de emissão.

Dado que a destruição térmica de resíduos é a maior fonte potencial de emissão de dioxinas, tem-se investido muito, ultimamente, na investigação sobre os mecanismos da sua formação [5] e sobre o modo de efectuar as reacções de combustão na maior extensão operacionalmente possível onde as técnicas de modelação em dinâmica de fluidos desempenham um papel fundamental. Como consequência, diversos incineradores de resíduos sólidos urbanos encontram-se já equipados com sistemas de termografia para monitorizar as condições de combustão junto às grelhas $\mathrm{e}$ com o objectivo de obter as condições óptimas de combustão. Nalguns casos, os dados registados pelos sistemas termográficos são interpretados por sistemas baseados em lógica difusa instalados em computadores, que fazem a regulação da alimentação de resíduos a serem incinerados, assim como da alimentação de ar primário e secundário e dos queimadores auxiliares. De um modo geral, tem-se verificado [3] que as instalações que têm sistemas deste tipo instalados apresentam menores emissões de óxidos de azoto, monóxido de carbono, partículas e dioxinas quando comparadas com condições operacionais idênticas e antes da instalação dos sistemas atrás referidos.
Outros desenvolvimentos recentes incluem a instalação de sistemas melhorados de injecção de calcário ou outros aditivos, melhores materiais filtrantes nos filtros de mangas, sistemas de destruição catalítica de dioxinas e lavadores de gases de alta eficiência.

Contudo, continua a ser necessário desenvolver sistemas de redução das emissões de dioxinas para as indústrias de processamento de metais não-ferrosos e do fabrico do aço, em que têm sido verificados poucos desenvolvimentos, quanto comparados com o caso da incineração de resíduos [6].

Por exemplo, na Alemanha, em que este último sector apresentou grandes desenvolvimentos no passado recente, as unidades de sinterização das siderurgias são responsáveis, já hoje, por maiores quantidades de dioxinas do que os incineradores de resíduos sólidos urbanos.

\section{Departamento de Engenharia Química, Instituto Superior Técnico, Av. Rovisco Pais. 1096 Lisboa Codex \\ 2 Centro de Tecnologias Ambientais, Instituto de Soldadura e Qualidade, Apartado 119 . 2781 Oeiras Codex}

\section{BIBLIOGRAFIA}

1. Fanelli, R., Garttini, S., "Human exposure to dioxin", New Horizons in Bilogical Dosimetry, 167, Wiley-Liss Eds., New York, 1991.

2. Crandall, M.S., Kinnes, G.M., Hartle, R.W., "Levels of chlorinated dioxins and furans in theree occupational environemnts", Chemosphere, 25,255 (1992).

3. Schwager, J. ; Appel, T., Pollution Engineering International, Summer 1999, 28.

4. Philipp, C.; "Dioxins", Enviro Service Int., Munique, 1999.

5. Bordado, J.C.M., Gomes, J.F.P.; Ingenium, II33, 95 (1999).

6. Bordado, I.C.M. ; Ferreira, H.M.S. ; Gomes, J.F.P., Química, 72, 15 (1999). 


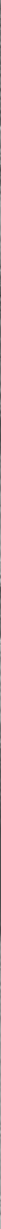

\section{MEDIDORES DE $\mathrm{pH}$ DE ALTA TECNOLOGIA FÁCEIS DE USAR E ECONÓMICOS}

\section{pH 300}

Medidor de $\mathrm{pH} / \mathrm{mV} /{ }^{\circ} \mathrm{C}$ de bancada

\section{pH 301}

Medidor de $\mathrm{pH} / \mathrm{mV} / \mathrm{iões} /{ }^{\circ} \mathrm{C}$ de bancada

\section{pH 302}

Medidor de $\mathrm{pH} / \mathrm{mV} /{ }^{\circ} \mathrm{C}$ de bancada com impressora

De acordo com as GLP

\section{From HANNA III. instruments ... of course ISO 9000 CERTIFIED}

Dos 700 funcionários do grupo Hanna, 130 estão ao seu serviço em Portugal.

PARA MAIS INFORMAÇÕES CONTACTE O NOSSO REVENDEDOR HANNA OU HANNAPRO EM VILA DO CONDE ATRAVÉS DO TEL. 052637184 / FAX 052637185 